\title{
Uso da ferramenta kodular no ensino de matemática para a educação básica
}

\author{
Felipe Becker ${ }^{1}$ \\ Hercules Affonso Karkow ${ }^{2}$
}

\begin{abstract}
Resumo: Este trabalho visou a realizar um experimento de forma qualitativa com uma docente da área de Matemática e sua turma do $2^{\circ}$ ano do Ensino Médio. $\mathrm{O}$ intuito foi complementar a didática das aulas e se aproximar da realidade social atual com relação ao uso da tecnologia com a utilização da ferramenta de desenvolvimento de projetos mobile chamada Kodular, como estudo de caso. Para a coleta de dados, foram aplicados questionários com perguntas objetivas e dissertativas tanto para a turma quanto para a docente, para saber a opinião deles sobre o uso de ferramentas tecnológicas nas escolas, além de entrevistas com a turma de discentes e a docente. E como resultados, em linhas gerais, após o uso da ferramenta, os alunos se mostraram motivados, com um índice maior de atenção para com os conteúdos da disciplina, inferindo assim que a ferramenta complementa seu processo de aprendizagem em sala de aula e de forma resumida, é algo que foge da rotina monótona realizada em algumas escolas, se tornando algo divertido e complementar.
\end{abstract}

Palavras-chave: Educação; Tecnologia; Crianças; Professores; Ensino de Matemática.

\section{Use of the Kodular tool in teaching mathematics for basic education}

\begin{abstract}
This work aimed to carry out an experiment in a qualitative way with a teacher in the area of Mathematics and her 2nd year high school class. The aim was to complement the didactics of the classes and get closer to the current social reality in relation to the use of technology with the use of the mobile project development tool called Kodular, as a case study. For data collection, questionnaires were applied with objective and dissertation questions both for the class and for a group of teachers to learn their opinion on the use of technological tools in schools, and interviews with the class of students and the teacher. And as a result, in general, after using the tool, the students were motivated, with a higher index of attention to the contents of the discipline, thus inferring that the tool complements their learning process in the classroom and in a way in short, it is something that escapes the monotonous routine performed in some schools, becoming something fun and complementary.
\end{abstract}

Keywords: Education; Technology; Children; Teachers; Mathematics Teaching.

\footnotetext{
${ }^{1}$ Doutor em Informática na Educação pelo Programa de Pós-Graduação em Informática na Educação (PPGIE) na Universidade Federal do Rio Grande do Sul (UFRGS). Mestre em Ciência da Computação pelo Programa de Pós-Graduação em Informática (PPGI) da Universidade Federal (UFSM) de Santa Maria (2014). Bacharel em Sistemas de Informação na Universidade Luterana do Brasil (ULBRA - Santa Maria) no ano de 2012. Professor na Antonio Meneghetti Faculdade. nunesfb@gmail.com.

2 heco_karkow98@hotmail.com.
} 


\title{
Uso de la herramienta Kodular en la enseñanza de matemáticas para la educación básica
}

\begin{abstract}
Resumen: Este trabajo tuvo como objetivo realizar un experimento de forma cualitativa con una profesora del área de Matemáticas y su clase de segundo año de secundaria. El objetivo fue complementar la didáctica de las clases y acercarse a la realidad social actual en relación al uso de la tecnología con el uso de la herramienta de desarrollo de proyectos móviles denominada Kodular, como caso de estudio. Para la recolección de datos se aplicaron cuestionarios con preguntas objetivas y de disertación tanto para la clase como para un grupo de docentes para conocer su opinión sobre el uso de herramientas tecnológicas en las escuelas, y entrevistas con la clase de estudiantes y el docente. Y como resultado, en general, luego de utilizar la herramienta, los estudiantes se motivaron, con un mayor índice de atención a los contenidos de la disciplina, infiriendo así que la herramienta complementa su proceso de aprendizaje en el aula y de alguna manera en definitiva, es algo que se escapa de la monótona rutina que se realiza en algunas escuelas, convirtiéndose en algo divertido y complementário.
\end{abstract}

Palabras clave: Educación; Tecnología; Niños; Maestros; Enseñanza de las matemáticas.

\section{Introdução}

O modelo educacional de muitas escolas ainda caminha de forma lenta para adequarse à tecnologia usada atualmente. Isso acarreta uma visão diferenciada dos professores em relação ao uso de recursos tecnológicos no ensino para com os alunos. Meneghetti (1996, p.85) traz a discussão sobre o impacto das tecnologias, criando-se diferenças enormes entre os analfabetos digitais e os experts sobre o uso dessas tecnologias, e aponta o líder como aquele capaz de gerar soluções para esse problema e promover evolução.

É notável que com o passado do tempo seja mais complicado para o professor aplicar todo o conteúdo proposto em sala de aula, muitas vezes pela questão do uso do celular por parte dos alunos de forma incorreta, mas também existe uma questão de comodidade que se estabeleceu na parte docente. Porém, um dos fatores desmotivadores para os alunos se dá pelo fato de que todo esse conteúdo está em livros que muitas vezes são espessos e que são apresentados de forma massiva. 
É preciso que haja uma comunicação em sala de aula, onde os tempos e espaços sejam valorizados de forma positiva, pois se almejamos uma nova proposta formativa é necessário que haja a desconstrução do paradigma transmissor, onde o livro didático seja única fonte de conhecimento e se construa um novo olhar pautado em um novo paradigma que dê conta das necessidades formativas emergentes. (SILVA et al., 2018, p. 03).

Entretanto, ainda pode ser considerado baixo o número de professores que vai em busca dessas novidades, pois como conta Villas Boas (2008, p. 33), as práticas da avaliação que se fundamentam nessas concepções pedagógicas, mais convencionais, denotam uma necessidade de atualização, no entanto elas estão tão impregnadas na cultura escolar que se torna extremamente difícil libertar-se delas. Existem várias ferramentas tecnológicas disponíveis para auxiliar os professores, tanto na organização como no desenvolvimento de seus conteúdos, e seria de extrema importância se em suas trajetórias para se tornar um docente, fosse complementada sua formação para a utilização de ferramentas tecnológicas.

Assim concretizaria a ideia de que é relevante construir caminhos direcionados a uma prática pedagógica inovadora, que dê sustentação a uma aprendizagem de qualidade na construção de uma boa prática de ensino, é preciso pensar a formação de professores e seus contributos para o sucesso escolar. (OLIVEIRA et al., 2019, p. 1).

Com elas, poderiam otimizar o tempo para a preparação das aulas e iriam trazer novas propostas de ensino, em que os alunos estarão ansiosos em relação às novidades, principalmente em áreas popularmente consideradas de maior dificuldade, como é o caso da Matemática. De certa forma, o que acaba desestimulando muitos alunos no seu desenvolvimento lógico é a forma como os professores passam o conteúdo, que na maioria das vezes não condiz com a atualidade em que vivemos.

É comum que isto ocorra no ensino de Matemática e é inegável que nos vem à memória a dificuldade de aprender a disciplina durante a educação básica. Para muitos, a dificuldade se perpetua no ensino superior.

Tais dificuldades se desenvolvem durante as aulas de Matemática, alguns alunos sentem-se insatisfeitos com relação à disciplina, por não gostar e ter dificuldade em aprender, e percebemos que o ensino de Matemática está baseado de forma tradicional, onde ensinam apenas com livros, resoluções de problemas, e muitas vezes o ensino se dá pelo meio transmissor e receptor, ou seja, o professor transmite e o aluno recebe como forma de uma aprendizagem bancária. (SILVA et al., 2018, p. 207). 
$\mathrm{Na}$ área da Matemática, muitos alunos têm dificuldade em prestar atenção enquanto a professora está explicando o conteúdo ou os motivos da utilização da fórmula que está sendo apresentada. Podem estar relacionadas a impressões negativas oriundas das primeiras experiências do aluno com a disciplina, à falta de incentivo no ambiente familiar, à forma de abordagem do professor, a problemas cognitivos, a não entender os significados, à falta de estudo, entre outros fatores (PACHECO e ANDREIS, 2018, p. 106).

Diante disso, dentre as alternativas viáveis, está a utilização da ferramenta Kodular ${ }^{3}$, que é disponibilizada gratuitamente, bastando apenas um acesso no navegador do computador e uma sincronização com o aplicativo dela, que é instalado no smartphone, possibilitando assim, uma forma diferenciada de o professor apresentar os conteúdos e “prender” a atenção dos alunos com esta prática. O Kodular é uma ferramenta que se encaixa neste processo; com ele, o professor consegue mostrar passo a passo seu conteúdo, onde os alunos poderão ver na prática o desencadear dos resultados do que eles estão aprendendo.

Dessa forma, o presente trabalho articulou a seguinte problemática de pesquisa: Como a ferramenta Kodular pode contribuir para o ensino de Matemática? A partir dessa indagação, foi possível definir o objetivo do trabalho, que é analisar as contribuições e limitações que a ferramenta de desenvolvimento mobile Kodular possui no ensino Matemático.

\section{Desenvolvimento Teórico}

Conforme conta Zanatta (2015, p. 22), para muitos pais, a criança ainda deve fazer coisas que somente as crianças fazem como brincar de boneca, carrinho, ou de escondeesconde, porém, esta perspectiva mudou, à medida que o mundo inteiro sofre uma reviravolta. Com todas essas informações vindas de todos os lados, não cabe mais impedir os pequenos de aproveitarem o que há de interessante e que vá lhes ajudar a desenvolver suas capacidades de forma mais centrada e civilizada. Contudo, não é simplesmente entregar-lhe um dispositivo eletrônico com acesso à internet e não mais orientá-lo, é preciso sempre estar atento para que seja utilizado de maneira correta.

Existem maneiras para lidar com essa situação, como uma troca. Por exemplo, para que ele possa utilizar o computador, precisa primeiro fazer o dever de casa, ou qualquer

\footnotetext{
${ }^{3}$ Kodular. Disponível em: https://www.kodular.io/
} 
outro tipo de atividade que lhe mostre que há outras formas de se distrair, não só diante de um smartphone ou computador. Pereira $(2017$, p. 09) aponta que diante de várias pesquisas podemos concluir que não devemos banalizar a tecnologia na vida das crianças, mas educar para fazerem o uso delas corretamente, pois assim não teremos analfabetos digitais e nem crianças viciadas.

De forma geral, canalizando as informações, para que o aprendizado dessas crianças em conjunto com a tecnologia possa ocorrer de forma satisfatória no ramo educacional, seria de extrema importância que os professores realizassem essa iniciativa e usassem os recursos disponíveis nas escolas, por mais limitados que sejam, para que isso se torne realidade e possa ocorrer de forma construtiva. Especialmente em áreas consideradas mais críticas, como é o caso da Matemática, em que o incentivo para o uso da tecnologia em sala de aula pelos professores nas aulas de Matemática está descrito na nova BNCC, que ressalta essa tendência desde os anos iniciais, onde se utiliza dos recursos básicos da tecnologia e ao longo dos anos cabe um aprofundamento das variedades tecnológicas mais complexas, como por exemplo, a programação, os algoritmos, visando a criar um pensamento mais apurado, computacional.

Além disso, a BNCC propõe que os estudantes utilizem tecnologias, como calculadoras e planilhas eletrônicas, desde os anos iniciais do Ensino Fundamental. Tal valorização possibilita que, ao chegarem aos anos finais, eles possam ser estimulados a desenvolver o pensamento computacional, por meio da interpretação e da elaboração de algoritmos, incluindo aqueles que podem ser representados por fluxogramas. (BNCC, 2018, p. 528)

Ou seja, é determinante a forma como o professor, seja ele de Matemática ou de qualquer outra disciplina, elabora, organiza e ministra suas aulas. Isso acaba de certa forma refletindo na qualidade da escola, tornando-a um ambiente muito mais atrativo e de referência. Há uma vasta variedade de soluções tecnológicas gratuitas no mercado e que podem ser utilizadas para auxiliar na educação, prendendo a atenção das crianças nos professores e buscando desencadear a sua lógica e criatividade para com o dia a dia e em relação às matérias passadas em aula.

O Kodular permite criar aplicativos Android facilmente com um editor de blocos, sem necessitar de nenhuma habilidade de codificação. Ela faz parte de um grupo de ferramentas que permite a um usuário sem muito conhecimento técnico ou em linguagem de 
programação, desenvolver um aplicativo para o smartphone com o simples ato de arrastar componentes em uma tela em branco.

Os componentes podem ser arrastados e utilizados sobre a tela, sendo os elementos básicos de qualquer interface de um aplicativo, como por exemplo, caixas de texto, botões laterais ou flutuantes em um menu, lista de seleção etc. Além disso, as aplicações criadas com o Kodular possuem uma interface mais amigável pelo fato de utilizarem uma linguagem para projetar interfaces criada pela Google e chamada Material Design. O mais interessante disso tudo é a forma de programar as ações e a lógica com que serão realizadas dentro da aplicação através de "blocos". Esses elementos são responsáveis por realizar todos os comados da aplicação por meio da interação com o usuário e funcionam como um "quebracabeça".

\section{Aplicação Metodológica}

O presente trabalho é caracterizado por um estudo de pesquisa de natureza qualitativa. Segundo Lüdke e André (1986), a pesquisa qualitativa é também denominada naturalística, pois [...] pressupõe o contato direto e prolongado do pesquisador com o ambiente e a situação que está sendo investigada, através do trabalho intensivo de campo (Lüdke; André, 1986, p. 11-12). Ele usa o critério qualitativo por querer buscar a ideia de que o uso da ferramenta pode proporcionar uma visão diferente, mais atrativa, para com os alunos em sala de aula e uma dinâmica mais moderna e fácil para o professor praticar.

\subsection{Participantes}

Participou da pesquisa a Professora de Matemática da Escola Estadual de Educação Básica de uma cidade do interior do Rio Grande do Sul. Ela é docente há seis anos, lecionando tanto a disciplina de Matemática quanto as disciplinas de Química e Ensino Religioso. Ela é um dos poucos docentes da escola que buscam mudar a forma de ensino de suas aulas.

Também fizeram parte da pesquisa a turma desta docente, que conta com 19 alunos de $2^{\circ}$ Ano do Ensino Médio com idades entre 16 e 19 anos. Turma essa que, segundo a professora, é bem dividida em questão de conhecimento e vontade de estudar. Metade da turma é bem aplicada e interessada sobre as novidades em sala de aula e possui um 
desenvolvimento um pouco mais avançado; diferente da outra metade, que não se interessa muito e não possui muita vontade de estudar, causando assim um desempenho em sala de aula mais baixo.

\subsection{Design do Estudo}

Os primeiros passos desenvolvidos para este trabalho englobaram a realização de pesquisas bibliográficas sobre o uso de ferramentas tecnológicas em sala de aula pelos alunos e professores, desde especificamente da área da Matemática como também de outras matérias. Também houve conversas com pessoas de referência sobre o tema e que já realizaram trabalhos semelhantes a esse. Começou-se então um estudo sobre a ferramenta de desenvolvimento mobile Kodular, utilizada pelos alunos do programa, onde notou-se ser um grande potencial para complementar a didática dos professores da área, assim como resgatar a atenção dos alunos para com a ferramenta utilizada, principalmente na área da Matemática.

A partir disso foi feito um estudo sobre a ferramenta Kodular pelo pesquisador. Depois, criou-se um protótipo de aplicativo que utilizasse alguns dos principais recursos da ferramenta, tais como os componentes da interface, os componentes lógicos e os blocos para a realização das ações da aplicação. Nesse estudo verificamos que os conceitos de operações numéricas e funções trigonométricas, estudadas em Matemática, poderiam ser exploradas pela ferramenta. Por isso, procuramos uma professora de Matemática da Educação Básica, que de agora em diante denominaremos "Docente X", a fim de preservar sua identidade e resguardar as questões éticas desse trabalho, para realizar uma entrevista e saber das possibilidades de usar essa ferramenta com os seus alunos.

A professora mencionou desconhecer essa ferramenta. Então, decidimos fazer uma capacitação sobre o Kodular com ela. A capacitação ocorreu em quatro módulos, sendo cada um deles com duração de 1 hora em diferentes dias, organizados no seguinte modo:

- $1^{\circ}$ Módulo: abordagem dos componentes de UI da ferramenta Kodular.

- $2^{\circ}$ Módulo: abordagem dos componentes em forma de Blocos para realização das ações lógicas do aplicativo.

- $\quad 3^{\circ}$ Módulo: envio de um pequeno protótipo de aplicativo para a professora, para que fosse adaptado e utilizado por ela em sala de aula com os alunos, como um meio de apresentação da ferramenta pela professora. 
- $4^{\circ}$ Módulo: esclarecimento de dúvidas para com a ferramenta e tratamento de erros para com uma das operações matemáticas, que foi relatado pela professora e feita a análise.

Dada essa capacitação para a professora, foi possível realizar, através dela, o mesmo procedimento para com os alunos, que passaram a utilizar a ferramenta como um meio auxiliar de aplicação prática do conteúdo teórico, em que a intervenção do autor foi somente para sanar algumas dúvidas durante o projeto. Cada aula da professora com os alunos teve duração média de 40 a 50 minutos, realizadas nos meses de outubro e novembro, no turno da manhã e na disciplina de Matemática. E como forma de alcançar os objetivos aqui propostos e solucionar o problema de pesquisa, as aulas foram organizadas da seguinte maneira, conforme Quadro 1.

\begin{tabular}{|c|c|}
\hline Projeto /aulas & Objetivos e descrições da experiência \\
\hline Aula 1 & $\begin{array}{l}\text { Uso da ferramenta Kodular para os alunos mostrando seu } \\
\text { funcionamento, comandos básicos e exemplos. Esta } \\
\text { apresentação para os alunos ocorreu da mesma forma a qual } \\
\text { foi para a Docente X, mas foi realizado por ela em sala de } \\
\text { aula. }\end{array}$ \\
\hline Aula 2 & $\begin{array}{l}\text { Exploração do Kodular pelos estudantes com o } \\
\text { acompanhamento da Docente X. }\end{array}$ \\
\hline Aula 3 & $\begin{array}{l}\text { Resolução de problema com a compilação da ferramenta e } \\
\text { com a instalação em determinados celulares. }\end{array}$ \\
\hline Aula 4 & $\begin{array}{l}\text { Instalação do aplicativo gerado como forma de calculadora } \\
\text { para auxiliar nas resoluções matemáticas pelos alunos. }\end{array}$ \\
\hline Aula 5 & Permitido o uso do aplicativo durante a aula de Matemática. \\
\hline Aula 6 & Permitido o uso do aplicativo durante a aula de Matemática. \\
\hline Aula 7 & Permitido o uso do aplicativo durante a aula de Matemática. \\
\hline Aula 8 & $\begin{array}{l}\text { Uso do aplicativo no final de uma avaliação como forma de } \\
\text { conferir os resultados. }\end{array}$ \\
\hline Aula 9 & $\begin{array}{l}\text { Aplicação do questionário final para avaliação da ferramenta } \\
\text { e realização das entrevistas com os alunos e a Docente X. }\end{array}$ \\
\hline
\end{tabular}


Trata-se de um Quadro que demonstra os passos realizados para atingir o objetivo proposto, com as aulas realizadas pela Docente $\mathrm{X}$ com os alunos, juntamente com o uso da ferramenta proposta como um meio agregador da disciplina. Em paralelo às aulas realizadas, foram aplicados os questionários com os alunos e posterior análise de como foi a experiência destes com o uso da ferramenta Kodular durante as aulas de Matemática.

Por fim, após a realização das aulas e da coleta das informações através de questionários e entrevista, foi realizada a análise dos dados que contou com uma avaliação da parte deles para com o uso da ferramenta Kodular em sala de aula, com o objetivo de auxiliá-los na disciplina de Matemática; também foi avaliado o ponto de vista da Docente $\mathrm{X}$, com relação à reação dos alunos em sala de aula com o uso desta abordagem.

\subsection{Instrumentos de Coleta de Dados}

A coleta de dados foi realizada através de entrevistas, tanto com os alunos quanto com a Docente $\mathrm{X}$, e da aplicação de dois questionários, sendo o primeiro deles com sete questões objetivas e uma questão dissertativa, para aplicação nos alunos no início do experimento, com o objetivo de analisar para quais fins estão sendo utilizados os aparatos tecnológicos deles, e ter uma base sobre a utilização de recursos tecnológicos por parte da professora em sala de aula.

O segundo questionário foi novamente aplicado aos alunos ao final do experimento, com o objetivo de verificar quais foram os seus pontos de vista para com a utilização da ferramenta Kodular durante as aulas, tanto como uma forma de aprendizado, como também como diversão. Tal questionário contou com nove questões objetivas e duas questões dissertativas e foi aplicado de forma online através do Google Forms. No final, também foram realizadas entrevistas separadamente com os alunos e a professora, a fim de garantir uma coleta de dados de ambas as partes, sem que houvesse uma repreensão de nenhum dos lados.

\section{Resultados e Discussão}


Essa seção tem por objetivo apresentar os resultados do desenvolvimento do projeto de pesquisa realizado com uma turma de $2^{\circ}$ ano de Ensino Médio e uma docente da área de Matemática de Escola Pública de uma cidade localizada no centro do Rio Grande do Sul.

\subsection{Avaliação para com os Alunos Quanto ao Uso de Aparelhos Tecnológicos e Aplicativos em Sala de Aula}

Nesta seção foi realizada uma pesquisa inicial com os alunos do experimento para saber a opinião deles sobre o uso de aparelhos tecnológicos ou aplicativos pelos professores e alunos em sala de aula. Para isso, foi aplicado um questionário inicial contendo oito questões, sendo sete objetivas e uma dissertativa.

A primeira pergunta teve o objetivo de saber se os alunos estão conseguindo aprender o conteúdo das aulas de Matemática da forma tradicional com que a professora adota. Os resultados foram os seguintes:

- Oito alunos, representando 31,58\%, apontaram que estão conseguindo aprender totalmente bem com a forma tradicional;

- Dez alunos, representando 52,63\%, apontaram que aprendem de forma parcial;

- Os outros três alunos, representando 15,79\%, apontaram que não estão conseguindo aprender muito bem com a forma tradicional.

Isso mostra que com a Docente $\mathrm{X}$, os alunos ainda conseguem aprender bem com a forma tradicional que ela ainda executa, mas também é possível notar que esta forma está começando a perder o efeito e possivelmente deixando os alunos menos atenciosos pela falta de novidades. A segunda questão era para saber se eles utilizavam de forma constante algum meio tecnológico em sala de aula, em que se mostraram equilibrados os níveis de utilização, como pode-se observar na Figura 1.

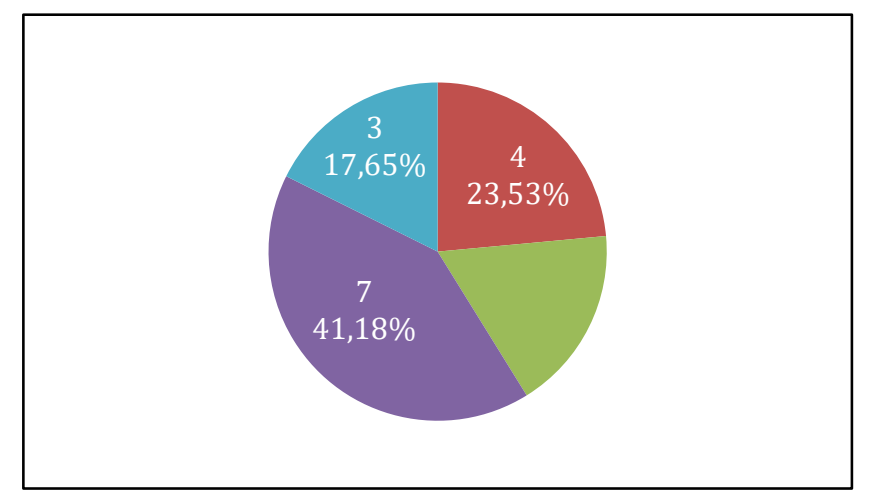

Figura 1: Representação gráfica em relação ao uso de dispositivos mobile em sala de aula. Fonte: Autores. 
Conforme mostra a Figura 1, os alunos estão bem diversificados quanto ao uso de dispositivos em sala de aula de forma constante. Dessas respostas, podemos ver que as aulas de Matemática com a Docente X são bem atrativas para os alunos, mesmo que ela não use muitos recursos tecnológicos, mas de alguma outra forma ela consegue prender a atenção da maioria dos alunos, a ponto de não usarem de forma constante os seus aparelhos no meio da aula.

Já a terceira pergunta tinha o objetivo de saber se eles teriam um alto grau de motivação para com o uso de algum aplicativo mobile para aprender o conteúdo da disciplina de Matemática, já como objetivo de prever se o uso da ferramenta Kodular seria produtivo dependendo das respostas dos alunos. As respostas se mostraram positivas, onde oito alunos representando $47,06 \%$ apontaram que ficariam totalmente motivados, outros cinco alunos representando 29,41\% apontaram que ficariam motivados de forma parcial e os outros quatro alunos representando $23,53 \%$ mostraram-se indiferentes ou que isso não os deixaria tão motivados.

Esses dados puderam mostrar que seria possível e mais fácil poder incluir o uso da ferramenta proposta para a pesquisa e que os alunos querem outras alternativas para seu aprendizado, o que os tiraria do conforto e os deixaria mais motivados a aprender. Tal motivação se deve ao fato de que:

\begin{abstract}
O contato dos alunos com fatos cotidianos possibilita que eles façam comparações, questionamentos, emitam juízos, assimilem conteúdos importantes, além de conduzirem a conclusões valiosas, ações estas bem diferentes daquelas produzidas por aquilo que lhes é imposto, que não lhes dá chance de análise crítica nem de expressar o que pensam. (MARTINS, 2009, p 22).
\end{abstract}

A quarta questão foi para saber se eles achariam divertido o uso de aplicativos mobile nas aulas para aprender o conteúdo de Matemática, com o intuito de ser uma forma que consiga prender a atenção dos alunos e fazer com que eles estejam aprendendo, sem nem mesmo perceber. $\mathrm{O}$ resultado se mostrou positivo conforme mostra a Figura 2. 
Figura 2 - Representação gráfica em relação à opinião dos alunos para o quão divertido seria o uso de aplicativos em sala de aula complementando a aprendizagem. Fonte: Autores.

Como pode-se observar, a Figura 2 mostra que grande parte dos alunos consideraria total ou parcialmente divertido o uso de aplicativos mobile em sala de aula como uma forma de complementar o seu aprendizado. Isso mostra que eles estão querendo algo que os ensine de maneira que seja prazeroso para eles, e não algo que os "crucifique" e os prenda na sala de aula a fazer algo repetitivo e cansativo que possui pouco resultado significativo, ou melhor, poucos alunos apresentam resultados significativos, pois a grande maioria está dispersa e não tem interesse se não há novidades.

Isso também mostra que, caso seja utilizado algum aplicativo em sala de aula para o processo de ensino dos alunos, eles deixarão um pouco de lado aquilo que não lhes agrega valor para dar lugar a algo novo, ficando até melhor para o controle do professor. A quinta pergunta tinha por objetivo saber se o uso de tais aplicativos mobile auxiliaria no processo de aprendizagem nas aulas de Matemática, o que também influenciaria no uso da ferramenta Kodular com eles.

Essa questão também apresentou um resultado positivo quanto à opinião, que demonstra que os próprios alunos conseguem perceber em si mesmos que outros meios ou ferramentas disponíveis no mercado conseguem lhe atrair de forma que eles consigam aprender mais, mas que ainda assim há um pouco de dúvidas sobre a forma como isso seria abordado em sala de aula, o que influencia na resposta dada pelos $63,84 \%$ dos alunos.

A sexta questão tinha o objetivo de saber em que os alunos utilizam os seus aparelhos na maior parte do tempo na sala de aula, para ter uma noção de como é o uso deles, se é de forma correta, se usam os seus aparelhos para complementar seus estudos ou se é só para passar o tempo. De certa forma, essa pergunta complementa a questão de número 2, onde eles apontaram se o uso de tais aparelhos era de forma constante.

Os dados apontaram que os alunos usam os seus aparelhos voltados principalmente para as redes sociais, ficando essa opção em primeiro lugar com 85,71\%; em segundo lugar, com $81,82 \%$, ficou o uso para pesquisas quando solicitado. Já 71,43\% relataram usar para jogos. Essa pergunta era de múltipla escolha, onde os alunos colocaram um nível de uso para cada item, onde os três itens citados acima ganharam maior relevância.

Isso mostra que os alunos, por não estarem interessados nas aulas, acabam se distraindo com outros meios como o das redes sociais e dos jogos, usando como meio de 
pesquisa somente quando solicitado pela professora, ou seja, os alunos possuem os seus aparelhos em sala de aula, porém o seu uso está destinado em grande parte para fins não complementares para o seu ensino. E isso deve ser revisto pelos professores, visto que, segundo Moran (1995):

As tecnologias de comunicação não substituem o professor, mas modificam algumas das suas funções. A tarefa de passar informações pode ser deixada aos bancos de dados, livros, vídeos, programas em CD. O professor se transforma agora no estimulador da curiosidade do aluno por querer conhecer, por pesquisar, por buscar, a informação mais relevante. Num segundo momento, coordena o processo de apresentação dos resultados dos alunos. Depois, questiona alguns dos dados apresentados, contextualiza os resultados, os adapta à realidade dos alunos, questiona os dados apresentados. Transforma informação em conhecimento e conhecimento em saber, em vida, em sabedoria o conhecimento com ética. (MORAN, 1995, p. 25).

A sétima pergunta foi direcionada para saber se a professora utiliza alguns recursos tecnológicos em sala de aula na visão de seus alunos, dos quais 70,59\% relataram que ela não utilizava nenhum outro recurso tecnológico, já os outros $29,41 \%$ relataram que sim. Esses dados mostraram que grande parte da turma considerou que a Docente $\mathrm{X}$ não usa muito dos meios tecnológicos, além da ferramenta Kahoot, comentada pelos mesmos em sala de aula e pela própria docente em conversas paralelas, demonstrando o grande percentual dos alunos que já não considera mais o uso de tal ferramenta de grande valia e que espera novidades.

A última pergunta de forma dissertativa foi para saber a opinião dos alunos em relação ao uso de aplicativos mobile nas aulas de Matemática para auxiliar no aprendizado dos conteúdos. Grande parte dos alunos aponta que o uso desses recursos em sala de aula, na visão deles, auxiliaria no rendimento da turma de modo divertido, que chamaria a atenção deles e sairia do processo repetitivo ao qual estão acostumados.

Mas também, alguns acham que poderia atrapalhar, pois sabem que a turma poderá ter a tendência de usar seus aparelhos para outros fins, como o das redes sociais ou outros, de modo que se perca o real propósito. Após a aplicação deste questionário inicial, foi realizada uma aula ministrada pelo autor sobre a ferramenta Kodular como ilustra a Figura 3.

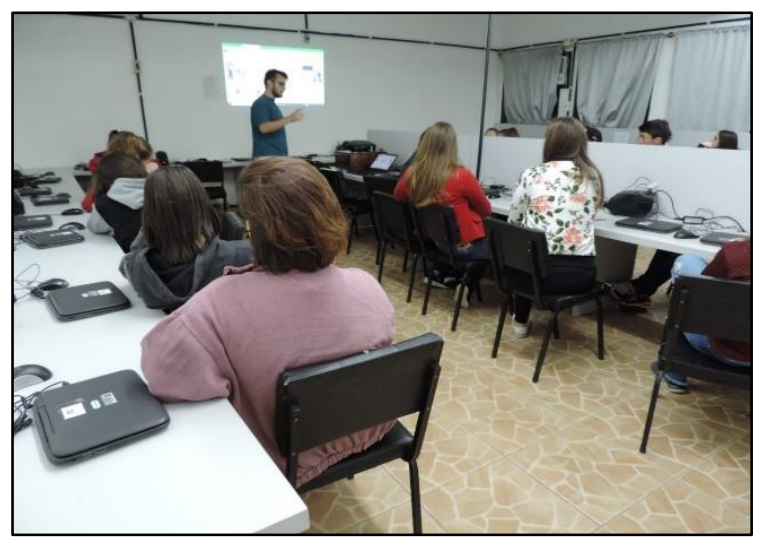


Figura 3 - Realização de aula com os alunos do experimento final sobre a ferramenta Kodular. Fonte:

Autores.

Esta aula ilustrada na Figura 3 teve por objetivo explicar o funcionamento da ferramenta Kodular para os alunos, assim como também os principais componentes e recursos, da mesma maneira que foram compostos os módulos realizados com a Docente X, porém de forma resumida para encaixar com o horário de aula deles.

\subsection{Avaliação dos alunos e da Docente $X$ para com o uso da ferramenta Kodular}

Após o uso da ferramenta Kodular tanto pelos alunos quanto pela Docente $\mathrm{X}$, foi realizada a aplicação de um questionário para a avaliação da ferramenta, com o objetivo de saber se houve alguma mudança por parte dos alunos, se gostaram de utilizá-la e se ela conseguiu atender às expectativas da professora.

O questionário foi composto por nove questões objetivas e duas dissertativas, onde a primeira pergunta questionou os alunos sobre o nível de satisfação deles quanto ao uso da ferramenta Kodular nas aulas de Matemática, com o objetivo de saber se foi algo relevante e se notaram algum diferencial. Os dados coletados foram os seguintes:

- $22,7 \%$ dos alunos responderam que ficaram totalmente satisfeitos com o uso da ferramenta.

- $40,9 \%$ responderam que ficaram parcialmente satisfeitos;

- $\mathrm{E}$ os outros $36,4 \%$ responderam de forma indiferente.

Esses dados demonstraram que o uso da ferramenta atingiu um nível de satisfação dos alunos de forma positiva, fazendo com que, tanto do lado da Docente $\mathrm{X}$ quanto do autor, fosse possível entender que o uso da ferramenta pode sim complementar a didática das aulas para com os alunos. $\mathrm{Na}$ segunda pergunta, os alunos foram questionados em relação ao quanto a ferramenta auxiliou no desempenho nas aulas de Matemática, para com a resolução de funções e equações dadas pelos conteúdos aprendidos, já com o intuito de mapear se na concepção deles houve uma melhora depois que passaram a utilizá-la. Seguem os dados coletados:

- $27,3 \%$ dos alunos responderam que o auxílio da ferramenta se deu de forma totalmente satisfatória; 
- $36,4 \%$ responderam que acham que a ferramenta auxilia de forma parcialmente satisfatória.

- $36,6 \%$ deles mostraram-se indiferentes;

- E um aluno, representando 4,5\%, acha que a ferramenta auxilia de forma parcialmente insatisfatória.

Os dados coletados mostraram que na visão dos alunos a ferramenta auxilia no desempenho nas aulas de Matemática; porém, os dados que representaram os alunos que responderam de forma indiferente ou insatisfatório foram relacionados a uma falha na aplicação para alguns deles, onde não foi possível instalar os aplicativos criados, ou por causa dos modelos dos dispositivos usados por eles, pela versão do Android, que possivelmente pode ser mais antiga, em que a ferramenta não suporta mais, ou ainda por alguns dos alunos utilizarem dispositivos IOS, o qual a ferramenta não trabalha ainda, mostrando assim o seu lado negativo. Mas de todo modo, para aqueles que conseguiram utilizar, a ferramenta cumpriu o seu papel mostrando que pode auxiliar no aprendizado dos alunos.

A terceira pergunta foi direcionada para saber a opinião dos alunos com relação ao nível de produtividade que obtiveram com uso da ferramenta Kodular nas aulas de Matemática. Seguem os dados resultantes:

- três alunos, representando $13,6 \%$ da turma, relataram que obtiveram uma produtividade bem satisfatória;

- onze alunos, representando 50\%, responderam que obtiveram uma produtividade em um nível parcialmente satisfatório;

- Outros 36,3\%, equivalente a oito alunos, onde sete deles responderam de forma indiferente, e outro de forma parcialmente insatisfatória.

Com isso, podemos dizer que o uso da ferramenta interfere de modo positivo na produtividade dos alunos, o que poderá auxiliar os professores com a entrega de seus conteúdos de modo que seus alunos compreendam aquilo que estão fazendo, e que eles consigam realizar suas tarefas com um grau de acerto maior e mais preciso, pois o uso da ferramenta mostrou-se eficaz para a criação de aplicativos que auxiliem na validação dos resultados dos exercícios dados em aula. Isso reflete o que diz Silva e Correa (2014, p. 30):

Se a educação, antes do surgimento tecnológico, já visava a agregação de valores aos conhecimentos produzidos e divulgados em sala de aula, com as tecnologias ela teria uma contribuição qualitativa que levaria a um crescimento não apenas 
econômico, no que cerne ao desenvolvimento de um país, mas também ao crescimento participativo e crítico das capacidades humanas (Silva e Correa, 2014, p. 30).

A quarta pergunta abordou o nível de praticidade para com o uso da ferramenta destinado à criação de uma aplicação de "calculadora" nas aulas de Matemática, bem como foi utilizado por eles. Aplicação esta que foi desenvolvida com o objetivo de resolver algumas questões sobre o conteúdo de trigonometria, como por exemplo, o resultado de determinado ângulo de Seno, Cosseno e Tangente, facilitando e agilizando as respostas dos alunos na aplicação em outras fórmulas utilizando os resultados obtidos pela aplicação.

Os dados novamente se mostram relevantes, como pode-se observar abaixo:

- $18,2 \%$ dos alunos apontaram que a praticidade com o uso da ferramenta se deu de forma totalmente satisfatória;

- $54,5 \%$ apontaram que foi de forma parcialmente satisfatória;

- Os outros $27,2 \%$, totalizando seis alunos, onde cinco deles responderam de forma indiferente, e o outro apontou ser parcialmente insatisfatório.

Esses dados mostram que a ferramenta Kodular apresenta-se de forma prática, simples e funcional na visão dos alunos para a criação de aplicativos que complementem a sua aprendizagem nas aulas de Matemática, de tal modo que poderá aumentar o nível das aulas, facilitando o processo de passagem de conteúdos da disciplina de um modo mais rápido. A quinta pergunta foi direcionada para o nível de impacto que a ferramenta Kodular usada como forma de complemento e aplicação dos conteúdos de Matemática poderá ocasionar sendo usada durante um ano letivo completo na opinião dos alunos. Os dados obtidos podem ser observados na Figura 4:

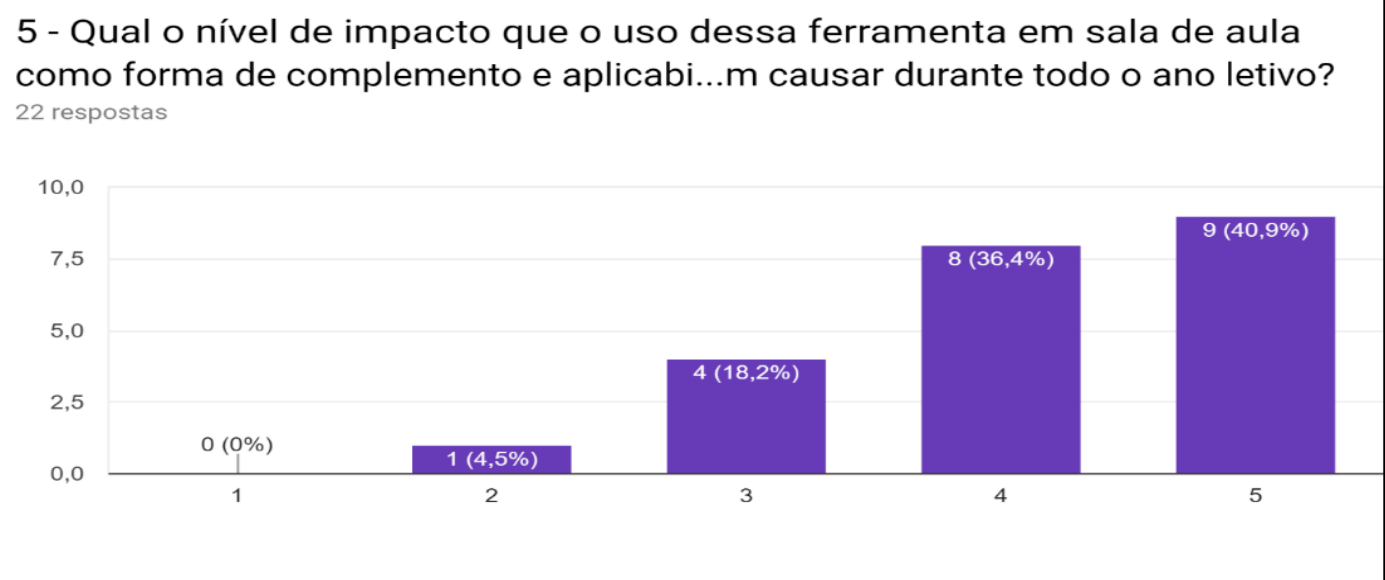


Figura 4 - Gráfico representado as respostas dos alunos para a questão de número 5. Fonte: Autores.

Podemos observar na Figura 4 que as respostas dadas pelos alunos atingiram um percentual positivo com relação à opinião deles ao uso da ferramenta durante um longo período, em que poderia se ter uma melhor experiência dela, onde a maioria $(40,9 \%)$ dos alunos opinaram que a ferramenta causaria impactos totalmente satisfatórios e outros $36,4 \%$ relataram que causaria impactos parcialmente satisfatórios. É possível notar que a perspectiva dos alunos é alta, podendo representar que a ferramenta poderá vir a ser utilizada mais à frente por eles de forma autônoma, ou também poderá haver uma solicitação por parte deles com os professores para com o uso mais constante em sala de aula.

Quando questionados na sexta pergunta sobre o quanto a ferramenta teria capacidade de contribuir com o desenvolvimento das demais disciplinas da Escola, os alunos se mostraram um tanto confiantes, como pode-se observar nos dados abaixo:

- $\quad$ seis alunos, representando $27,3 \%$ da turma, responderam que a ferramenta poderia contribuir de forma totalmente satisfatória com as demais disciplinas;

- nove alunos, representando 40,9\% da turma, responderam que ela poderia contribuir de forma parcialmente satisfatória;

- Outros $27,3 \%$ deles, totalizando seis alunos, responderam de forma indiferente.

Como é possível observar, os alunos conseguem notar que a ferramenta Kodular teria alguma capacidade de contribuir com o processo didático de outras disciplinas de diferentes áreas, mostrando que é uma ferramenta completa e flexível, cabendo a eles ou aos professores darem forma nas aplicações criadas para dar seguimento na abordagem de seus conteúdos. Na sétima pergunta foi questionado se os alunos continuariam motivados a usar a ferramenta da mesma maneira como estavam quando apresentada para eles. Essa pergunta teve o intuito de complementar a questão número 5 para possível uso da ferramenta mais à frente. Os dados obtidos foram os seguintes:

- $77,3 \%$ da turma responderam que continuaram motivados a utilizar a ferramenta tal qual no início;

- $22,7 \%$ responderam que não.

Isso demostrou que mesmo alguns dos alunos passando por alguns problemas durante o uso da ferramenta, grande parte deles continuou motivada da mesma forma como estava no início a utilizá-la novamente. Questionados na oitava pergunta se eles voltariam a utilizar 
a ferramenta para auxiliá-los, seja nas disciplinas da escola ou mesmo em casa, foi possível observar que a ferramenta conquistou os alunos, pois 90,9\% da turma responderam que voltariam a utilizar, já os 9,1\% restantes relataram que não. Para os que não voltariam a utilizá-la, percebe-se nas respostas das demais questões que foi por motivo de que para os aparelhos que eles possuíam, não havia suporte na ferramenta, impossibilitando que usassem. Já para aqueles que conseguiram, a ferramenta conseguiu passar boas impressões.

A nona pergunta destinou-se para com as impressões que o uso da ferramenta Kodular nas aulas de Matemática proporcionou, onde foi possível perceber quais alunos não conseguiram usá-la e para aqueles que conseguiram, segue as opiniões:

- Aluno A: "Bem direcionado ao aprendizado";

- Aluno B: "É um bom método de ensino e ajuda muito";

- Aluno C: "Segundo minha opinião, foi uma iniciativa muito válida, que desperta interesse dos alunos, não fica uma aula repetitiva. super aprovado";

- Aluno D: "Muito válido, pois os alunos estariam mais interessados";

- Aluno E: "Achei que ela tem uma forma muito simples de se utilizar e com isso muito eficiente".

É possível perceber que a ferramenta proporcionou aos alunos uma impressão positiva, pois através das respostas, os alunos comentam que ela é bem interessante, foge do processo repetitivo atual das aulas e disseram ser uma ferramenta bem eficiente. A décima pergunta buscou a opinião dos alunos se o uso da ferramenta nas aulas de Matemática despertou mais a atenção ou interesse da turma. Os resultados foram de $77,3 \%$ positivos e $22,7 \%$ negativos. Isso mostrou que grande parte da turma voltou a ter interesse nas aulas e passou a prestar mais a atenção. Isso significa que durante as aulas, a taxa de eficácia no aprendizado para grande parte dos alunos com relação aos conteúdos propostos pela disciplina será mais alta com o uso da ferramenta.

E, por fim, a última pergunta tinha por objetivo fazer com que os alunos descrevessem outras ferramentas tecnológicas de conhecimento deles e que gostariam que a escola adotasse ou utilizasse com mais frequência. Dentre as respostas, destacam-se as seguintes:

- Aluno A: "Uma agenda coletiva para as provas, que auxiliasse para lembrar dias antes.";

- Aluno B: "Provas online";

- Aluno C: "Descomplica, calculadora, mindmeinster". 
Essas respostas mostram que os alunos já pensam em processos de avaliação de forma online, pois já é algo do cotidiano deles fora da escola, se for pensar em níveis de qualificação, por exemplo. Outro ponto interessante dentre as respostas é que se preocupam com a questão da organização em que abordam o uso de ferramentas ou aplicações na forma de agendas, o que por um lado demostra que não estão tão alinhados com algumas ferramentas já disponíveis pelo própria Google, como por exemplo, o Google Classroom.

Seguido do questionário, a Docente $\mathrm{X}$ complementou por meio de entrevista realizada, também dizendo o seguinte: " $\mathrm{Eu}$, como professora, acho ela muito interessante, se vocês tiverem a oportunidade de continuar, vocês podem construir o que vocês precisam, [...]. Se vocês também se interessarem em procurar gente, para o ano que vem isso vai ser bem interessante para vocês criarem o que vocês precisam nela. Isso que é o mais legal, que vocês podem criar à necessidade de vocês.".

Questionada se continuaria a utilizar a ferramenta, ela afirma que sim, porém quando tiver com mais tempo e que pretende aplicar com os seus novos alunos do ano seguinte mais especificamente para os conteúdos de geometria, para montar fórmulas básicas para áreas, volumes e figuras. E com ela possuindo mais experiência com o uso da ferramenta, ela relata que conseguirá passar o conhecimento de forma melhor, fazendo com que os próprios alunos consigam montar sozinhos as suas aplicações e fortalecendo a ideia de que:

\section{[...] um conjunto de conhecimentos específicos, acumulados ao longo da história, sobre as diversas maneiras de se utilizar os ambientes físicos e seus recursos materiais em benefício da humanidade. Segundo essa definição, tecnologia abrange desde o conhecimento de como plantar e colher, passando pela fabricação de ferramentas, de pedra lascada ou aço inoxidável, até a construção de grandes represas e satélites. (SILVA; SILVA, 2006. p. 386)}

Com isso, podemos dizer que usar ferramentas tecnológicas como auxiliares na educação só agrega no processo de adquirir conhecimento, fazendo com que tanto professores quanto alunos consigam através dela construir algo para si que possibilite a sua expansão de conhecimentos. Em se tratando da ferramenta de desenvolvimento mobile Kodular, ela se mostrou valiosa para os alunos e uma forma diferenciada para os docentes ensinarem seus conteúdos de Matemática, de modo que faça sentido o uso das fórmulas e equações de seus exercícios para os alunos, servindo também como um comparador de seus resultados realizados de forma manuscrita. 


\section{Considerações Finais}

Conforme apresentado no presente trabalho, saber usar a tecnologia de forma correta é um desafio e tanto levando em consideração a grande quantidade de entretenimento que existe nas lojas de aplicativos atualmente, o que faz com que as crianças e adolescentes percam o foco da infância, juventude e também a atenção em sala de aula. Assim como, também gera certa restrição por parte de alguns professores para uso dela em sala de aula.

Com base nisso, foi realizado um trabalho utilizando a ferramenta Kodular para propor uma forma diferente do uso da tecnologia para com os alunos e uma abordagem diferente de ministrar aula pelos professores. Dessa forma, os objetivos desse trabalho foram atingidos com sucesso, tendo em vista as respostas adquiridas pelos alunos e pela docente através da aplicação dos questionários e das entrevistas realizadas.

Foi possível adquirir as impressões de que a ferramenta de fato consegue complementar a didática das aulas dos docentes e direcionar a atenção dos alunos aos conteúdos das disciplinas da escola, de forma divertida e diferente da atual tradicional. De tal modo que passa certa segurança para os alunos, pois eles podem realizar comparações de resultados entre o que eles desenvolveram manualmente, com os resultados dados pela aplicação que eles criaram através da ferramenta, garantindo uma maior integridade na resolução de exercícios em aula.

No contexto da área da Matemática, foi possível notar que a ferramenta pode auxiliar para a validação dos resultados manuscritos ao passar as equações utilizadas na disciplina para uma aplicação que realiza os cálculos automaticamente; isso garante ao aluno mais confiança no seu processo de aprendizagem nas resoluções dos cálculos matemáticos.

Para a docente, as impressões adquiridas foram que a ferramenta despertou os olhares dos alunos e que consegue complementar o processo de ensino de conteúdos para os alunos durante as aulas. Foi possível também perceber através dela que os alunos se interessaram pela ferramenta, como forma de visualização mais precisa dos seus resultados nas atividades. A docente também ressalta que pretende estudar de modo mais aprofundado a ferramenta, para poder auxiliá-la em suas próximas turmas com o objetivo de conseguir mesclá-la com suas aulas durante todo período letivo.

Dentre as limitações do trabalho, destacam-se a falta de infraestrutura da escola, que utiliza netbooks com processamento lento, a internet lenta, a falta de tempo por parte da Docente X, a limitação da ferramenta Kodular, que ainda não possui suporte para 
dispositivos IOS e que alguns alunos possuíam, o que inviabilizou o uso da mesma, e o curto período em que foi possível realizar a pesquisa.

Para projetos futuros, pretende-se fazer uma pesquisa mais aprofundada com um período mais longo de tempo, podendo ser feita uma análise mais construtiva e eficaz; também objetiva-se realizar um estudo para com a possibilidade de viabilizar esse experimento com escolas que não possuem nenhuma infraestrutura e baixo investimento. Por último, a tentativa de construir uma oficina para capacitação de docentes que procuram tornar suas aulas mais dinâmicas e atrativas para seus alunos, de forma mais organizada, apresentando a ferramenta Kodular e demais alternativas existentes neste escopo.

\section{Referências}

BRASIL. BNCC. Disponível em: http://basenacionalcomum.mec.gov.br/. Acesso em Dezembro de 2019.

LÜDKE, M.; ANDRÉ, M. E. D. A. Pesquisa em Educação: abordagens qualitativas. São Paulo: Editora Pedagógica e Universitária (EPU), 1986.

MARTINS, J. S. Situações práticas de ensino e aprendizagem significativa. 1. ed. Campinas: Autores Associados, 2009.

MENEGHETTI, A. Em Si da Arte e Criatividade. Psicologica Editrice, Florianópolis SC, Brasil, 1996.

MORAN, M. J. Novas Tecnologias e o reencantamento do mundo: tendências na educação. Revista Tecnologia Educacional, v. 23, n.126, p. 24-26, Rio de Janeiro, 1995.

OLIVEIRA, S. B.; TARGIINO, J. R. Desafios da Formação Continuada de Professores de Matemática nos Anos Finais do Ensino Fundamental. Id on Line Rev.Mult. Psic., v.13, n. 45, p. 773-783, 2019. 
PACHECO, M. B.; ANDREIS, G. S. L. Causas das dificuldades de aprendizagem em Matemática: percepção de professores e estudantes do $3^{\circ}$ ano do Ensino Médio. Revista Principia - divulgação científica e tecnológica do IFPB, nº 38, p. 1-10, 2017.

PEREIRA, F. M. Impactos da Utilização das Tecnologias no Processo de Aprendizagem das crianças. Id on Line Ver. Mult. Psic., v.11, n. 38, 2017.

SILVA, B. C.; BRAYNER, C.; BORRALHO, A. M. A. Avaliação em Matemática com uso de tecnologias no ensino médio na perspectiva de professores. V Congresso de Avaliação em Educação, Bauru/São Paulo, 2018.

SILVA, R. F; CORREA, E. S. Novas tecnologias e educação: a evolução do processo de ensino e aprendizagem na sociedade contemporânea. Educação \& Linguagem, ano 1, nº 1, p. 23-35, 2014.

SILVA, K. V.; SILVA, M. H. Dicionário de conceitos históricos. 2. ed. São Paulo: Contexto, 2006.

VILLAS BOAS, B. M. F. Virando a escola do avesso por meio da avaliação. São Paulo: Papirus, 2008.

ZANATTA, A. C. Programação de computadores para crianças metodologia do Code Club Brasil. Trabalho de Conclusão de Curso (Graduação em Tecnologias da Informação e Comunicação) - Universidade Federal de Santa Catarina, Araranguá, 2015. 